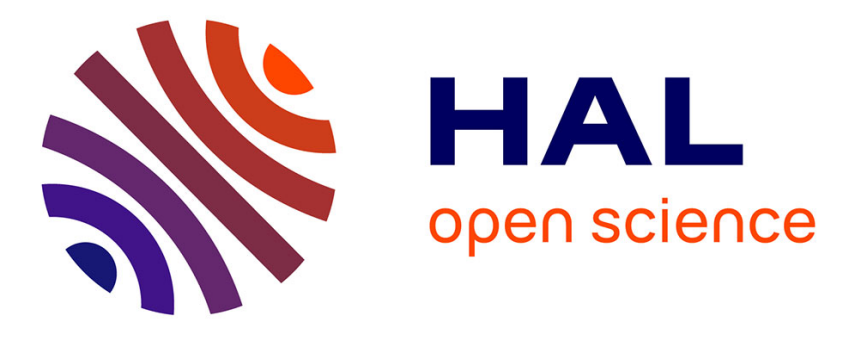

\title{
Double-Modulation Coherent Population Trapping Clock
}

Peter Yun, François Tricot, Claudio Calosso, Salvatore Micalizio, Moustafa Abdel Hafiz, Rodolphe Boudot, Emeric de Clercq, S Guerandel

\section{- To cite this version:}

Peter Yun, François Tricot, Claudio Calosso, Salvatore Micalizio, Moustafa Abdel Hafiz, et al.. DoubleModulation Coherent Population Trapping Clock. Conference on Precision Electromagnetic Measurements, Jul 2018, Paris, France. hal-02370696

\section{HAL Id: hal-02370696 https://hal.science/hal-02370696}

Submitted on 19 Nov 2019

HAL is a multi-disciplinary open access archive for the deposit and dissemination of scientific research documents, whether they are published or not. The documents may come from teaching and research institutions in France or abroad, or from public or private research centers.
L'archive ouverte pluridisciplinaire HAL, est destinée au dépôt et à la diffusion de documents scientifiques de niveau recherche, publiés ou non, émanant des établissements d'enseignement et de recherche français ou étrangers, des laboratoires publics ou privés. 


\title{
Double-modulation coherent population trapping clock
}

\author{
P. Yun ${ }^{*}$, F. Tricot, C. E. Calosso ${ }^{\dagger}$, S. Micalizio ${ }^{\dagger}$, M. A. Hafiz ${ }^{\dagger \dagger}$, R. Boudot ${ }^{\dagger \dagger}$, E. de Clercq, S. Guerandel \\ "NTSC, Chinese Academy of Science, East Shuyuan Road, Lintong, Xi'an, 710600, Shaanxi,China \\ †Istituto Nazionale di Ricerca Metrologica, INRIM, Strada delle Cacce 91, 10135 Torino, Italy \\ †'FEMTO-ST, CNRS, UBFC, 26 chemin de l'Épitaphe 25030 Besançon Cedex, France \\ LNE-SYRTE, Observatoire de Paris, PSL Paris Université, CNRS, Sorbonne Université, UPMC \\ 61 avenue de l'Observatoire, 75014 Paris, France \\ stephane.guerandel@obspm.fr
}

\begin{abstract}
Atomic clocks based on coherent population trapping and constructive polarization modulation are promising for high performance and compact devices. We have demonstrated a cw mode CPT clock with a short-term fractional frequency stability at the level of $3.2 \times 10^{-13} / \sqrt{\tau}$ for a few $100 \mathrm{~s}$ integration time. This Double-Modulation CPT technology can be reduced to a miniature and robust setup due to its linear architecture. This clock could find future applications in industry, telecommunications, instrumentation, or global navigation satellite systems.
\end{abstract}

Index Terms - coherent population trapping, atomic clock, frequency stability

\section{INTRODUCTION}

The constructive polarization modulation coherent population trapping (CPT) [1] is a promising way to implement a high performance compact CPT clock [2,3]. Here we report our progress towards a cw mode CPT clock with high performance.

\section{LASER POWER \& FREQUENCY LOCKING}

As a prerequisite for a clock implementation, we first need to stabilize the laser power and laser frequency, which is depicted in Fig. 1.

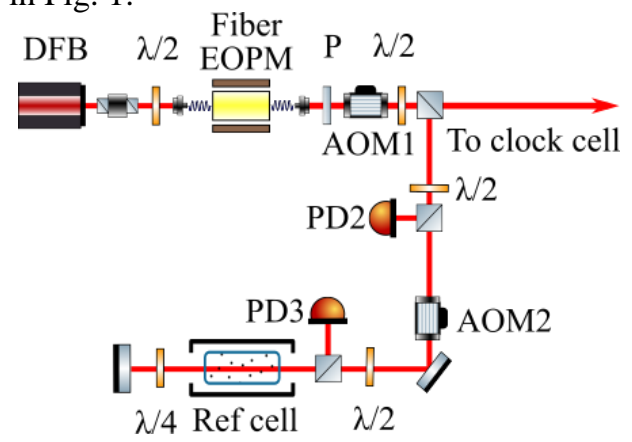

Fig. 1. Setup for laser power locking and laser carrier frequency locking.

It turns out the DFB diode laser in our setup is quite sensitive to back-reflections, e.g., even the coated collimated lens may induce some intensity and frequency noise in the range from $100 \mathrm{~Hz}$ to $10 \mathrm{kHz}$. A very careful alignment is needed to find a position that minimizes the lens-induced noise while keeping the laser beam collimation. To reduce the light feedback from
EOPM fiber input reflection, a $60 \mathrm{~dB}$ isolator before the EOPM is used as well. We measured the laser relative intensity noise (RIN) before and after the fiber EOPM, as demonstrated in Fig. 2. We can clearly find the fiber EOPM induces additional intensity noise between $1 \mathrm{~Hz}$ to $1 \mathrm{kHz}$. The relatively high intensity noisy laser has to be stabilized. With the setup shown in Fig. 1, we successfully suppress most of these noises, at least $15 \mathrm{~dB}$ in the range of $1 \mathrm{~Hz}$ to $1000 \mathrm{~Hz}$.

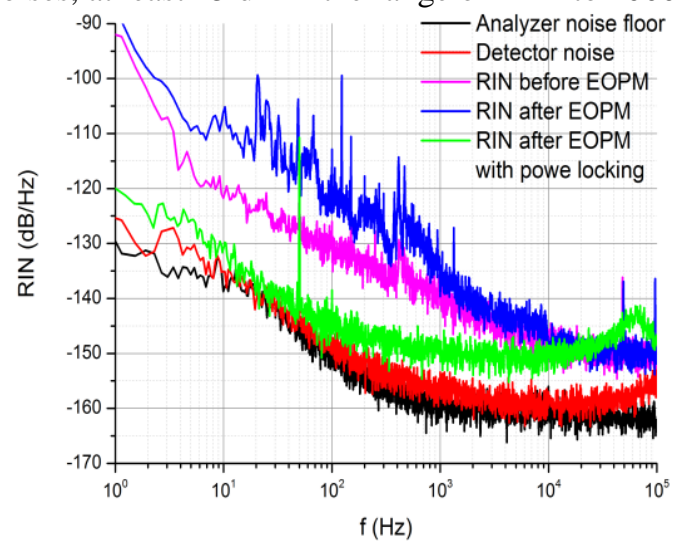

Fig. 2. The laser RIN before and after pass through the EOPM, in the latter case, the RIN with and w/o laser power locking are recorded, the detector noise and analyzer noise floor are also presented.

With a setup similar to [3,4], we observed the two-color Doppler-free spectroscopy in a pure cesium cell depicted in Fig. 3, thus we can lock the laser carrier frequency. The frequency noise with and without locking are presented in Fig. 4, from which we can find the servo bandwidth is about 3 $\mathrm{kHz}$.

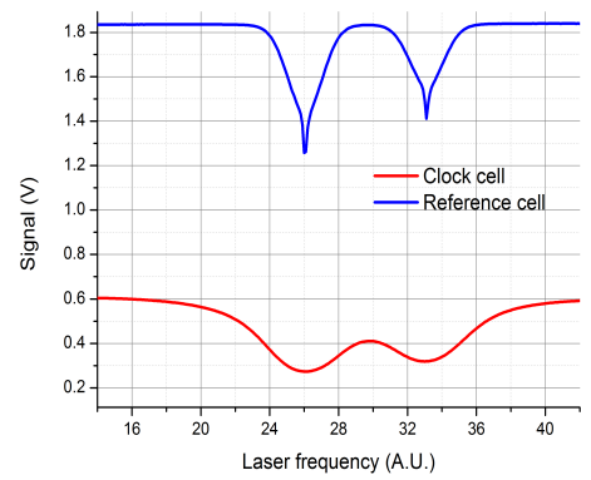

Fig. 3. Two-color spectroscopies in reference cell (pure Cesium) and clock cell ( Cesium plus buffer gas). 


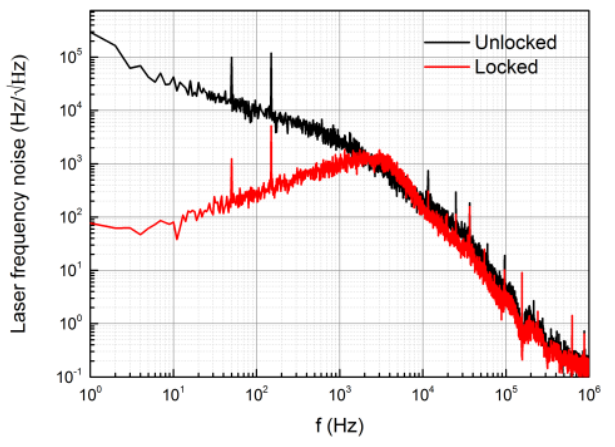

Fig. 4. The laser frequency noise with and w/o laser frquency locking.

\section{MAIN SETUP \& CLOCK LOCKING}

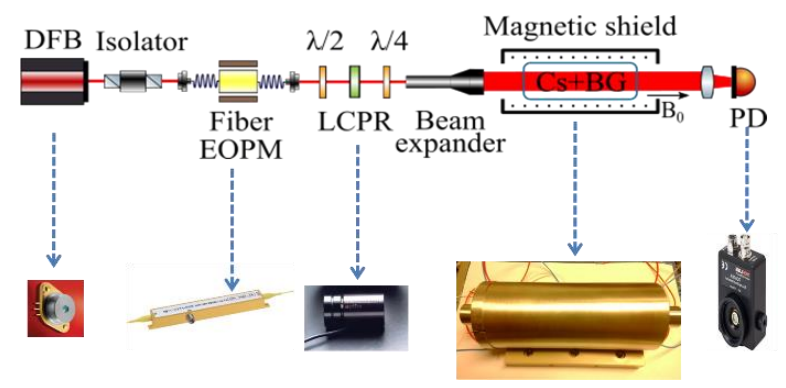

Fig. 5. Main setup and components for double-modulation CPT.

The Fig. 5 presented the main setup and components in our DM CPT, more detail can be found in [5]. The main difference in this studies are the following, the laser beam diameter is expanded to $9 \mathrm{~mm} \times 16 \mathrm{~mm}$ before the vapor cell. The cylindrical Cs vapor cell, $25 \mathrm{~mm}$ diameter and $50 \mathrm{~mm}$ long, is filled with 15 Torr of mixed buffer gas (argon and nitrogen). The cell temperature is stabilized to about $35^{\circ} \mathrm{C}$. In our experiment a uniform magnetic field of $3.43 \mu \mathrm{T}$ along the direction of cell axis is applied to remove the Zeeman degeneracy.

A typical CPT signal of clock transition is presented in Fig 6, with contrast $5.6 \%$ and linewidth $385 \mathrm{~Hz}$.

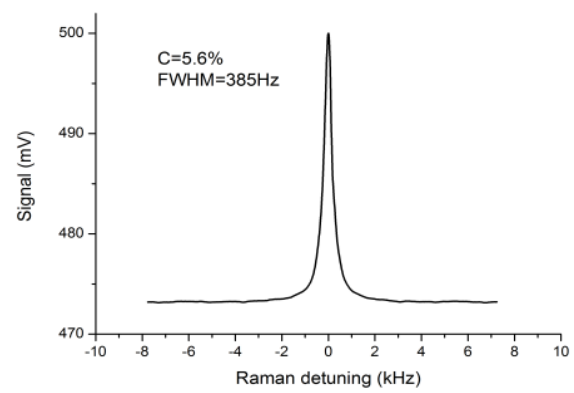

Fig. 6. Typical CPT clock signal.

With this relatively high contrast and narrow linewidth CPT signal, we lock our local oscillator frequency to the atomic vapor reference, and compare it with a hydrogen maser frequency standard. A first result recorded in Fig. 7 shows the frequency stability averages as $3.2 \times 10^{-13} / \sqrt{\tau}$ up to the 100 seconds integration time [6]. This short-term frequency stability performance is very close to the best CPT clocks. Further study will focus on the improvement of mid-term and long-term frequency stability.

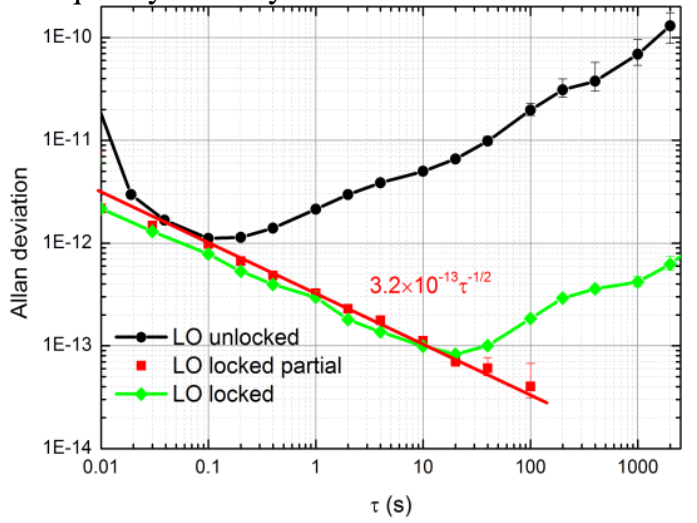

Fig. 7. Allan deviation of our DM CPT clock.

\section{CONCLUSION}

We have demonstrated a cw CPT clock with polarization modulation, a short-term frequency stability of $3.2 \times$ $10^{-13} / \sqrt{\tau}$ utill 100 second is measured. This results clearly demonstrated the feasibility to implement a high performance and compact CPT clock based on polarization modulation.

\section{ACKNOWLEDGEMENT}

We would like to thank Rodolphe Boudot, Moustafa Abdel Hafiz, Luca Lorini for helpful discussions. We are also pleased to acknowledge José Pinto Fernandes, Michel Lours, Pierre Bonnay and Annie Gérard for technical assistance.

\section{REFERENCES}

[1] P. Yun, J.-M. Danet, D. Holleville, E. de Clercq, and S. Guérandel, "Constructive polari-zation modulation for coherent population trapping clock," Appl. Phys. Lett. 105, 231106, 2014.

[2] J.-M. Danet, O. Kozlova, P. Yun, S. Guérandel and E. de Clercq, "Compact atomic clock prototype based on coherent population trapping," EPJ Web of Conferences, 77, 00017 (2014)

[3] Abdel Hafiz M and Boudot R, "A coherent population trapping Cs vapor cell atomic clock based on push-pull optical pumping," J. Appl. Phys. 118, 124903, 2015

[4] Moustafa Abdel Hafiz, Grgoire Coget, Emeric De Clercq, "Doppler-free spectroscopy on the Cs D1 line with a dualfrequency laser," Rodolphe Boudot, Optics Letters, 41, 29822985(2016).

[5] P. Yun, F. Tricot, D. Holleville, E. de Clercq, and S. Guérandel, "A compact setup for double-modulation coherent population trapping clock," 30th EFTF, York, 2016.

[6] P. Yun, F. Tricot, C. Calosso, S. Micalizio, B. François, R. Boudot, S. Guérandel, E. de Clercq, "High-performance coherent population trapping clock with polarization modulation” Phys. Rev. Appl., 7, 014018 (2017) 